\title{
PENENTUAN LOKASI INDUSTRI BIOMASS PELLET (BIOPELLET) BERDASARKAN METODE PERBANDINGAN EKSPONENSIAL DI KABUPATEN JEMBER
}

\author{
Andrew Setiawan Rusdianto \\ Fakultas Teknologi Pertanian, Universitas Jember \\ Korespondensi: Jln. Kalimantan 37, Jember 68121 \\ Email: andrew-sca@ hotmail.com
}

\begin{abstract}
Limbah biomassa dipilih sebagai sumber energi alternatif karena ketersediaan bahan yang berlimpah, murah, serta renewable.Salah satu jenis biomassayang dapat digunakan sebagai bahan bakar adalah limbah dari ubi kayu yang di dapat dari berbagai indutri olahan ubi kayu, terutama di daerah Kabupaten Jember.Pemanfaatan ubi kayu dalam industri akan menghasilkan beberapa output salah satunya yakni berupa limbah padat yang berupa kulit dan bonggol yang potensial digunakan sebagai bahan baku industri biopellet. Penelitian ini bertujuan untuk menentukan lokasi potensial untuk mendirikan industri biopellet di Kabupaten Jember.Penelitian ini dilaksanakan di Kabupaten Jember.Metode pengambilan data antara lain metode wawancara (interview), observasi dan studi pustaka. Analisis pemilihan wilayah potensial untuk mendirikan industri menggunakan Metode Perbandingan Eksponensial (MPE).

Wilayah yang paling potensial untuk dikembangkan menjadi industri biopellet yaitu di wilayah Kecamatan Jelbuk dengan nilai akhir sebesar 202.836.Kecamatan Jelbuk layak menjadi wilayah potensial karena mempunyai banyak unit usaha olahan tape singkong yang juga dapat menghasilkan banyak limbah ubi kayu. Terdapat 30 unit usaha tape singkong yang terdaftar di Dinas Koperasi Kabupaten Jember yang menduduki unit usaha tape singkong terbesar kedua setelah Kecamatan Tanggul dengan 35 unit usaha. Kecamatan ini juga termasuk memiliki harga tanah yang murah dibanding dengan wilayah lainya, data sekunder dari Bank Danamon tahun 2014 menunjukkan harga tanah di Kecamatan Jelbuk yakni sebesar Rp $100.000 / \mathrm{m}^{2}$.
\end{abstract}

Keywords: kulit ubi kayu, Industri biopellet, penentuan lokasi, perbandingan eksponensial

\section{PENDAHULUAN}

Biomassa sangat potensial untuk dikembangkan menjadi energi terbarukan dengan melakukan konversi biomassa menjadi bahan bakar (Hadiwiyoto,2009).Limbah biomassa dipilih sebagai sumber energi alternatif karena ketersediaan bahan yang berlimpah, murah, serta renewable.Salah satu jenis biomassayang dapat digunakan sebagai bahan bakar adalah limbah dari ubi kayu yang di dapat dari berbagai indutri olahan ubi kayu, terutama di daerah Kabupaten Jember.

Badan Pusat Statistik (BPS) Kabupaten Jember pada tahun 2014 menyatakan produksi ubi kayu pada tahun 2011 sebesar 49.678 ton, pada tahun 2011 sebesar 47.803ton, dan pada tahun 2013 sebesar 41.560ton.Para pelaku usaha memanfaatkan ubi kayu menjadi produksi tepung gaplek, tape ubi kayu, dan keripik ubi kayu.Menurut DISPERINDAG dan ESDM serta DINKOP dan UMKM Kabupaten Jember tahun 2013 menyatakan bahwa industri pengolahan ubi kayu terdapat 15 unit dan jumlah ubi kayu yang dimanfaatkan berjumlah 808 ton. Pemanfaatan ubi kayu dalam industri akan menghasilkan beberapa output salah satunya yakni berupa limbah padat yang berupa kulit dan bonggol yang potensial digunakan sebagai bahan baku pembuatan biopellet.

Pendirian industri biopellet di Kabupaten Jember membutuhkan uji kelayakan untuk menilai apakah industri ini layak atau tidak untuk dijalankan. 
Penentuan lokasi merupakan salah satu komponen yang ada di dalam kajian kelayakan industri biopellet. Kesalahan di dalam proses penentuan lokasi industri akan menimbulkan berbagai dampak baik dampak internal (seperti kerugian pendapatan) maupun dampak eksternal (seperti pencemaran lingkungan sekitar)(Karoror, 2007).Penelitian ini bertujuan untuk menentukan lokasi potensial untuk mendirikan industri biopellet di Kabupaten Jember.

\section{METODE PENELITIAN}

Penelitian ini dilaksanakan di Kabupaten Jember.Metode pengambilan data antara lain metode wawancara (interview), observasi dan studi pustaka. Analisis pemilihan wilayah potensial untuk mendirikan industri diolah dengan menggunakan Metode Perbandingan Eksponensial (MPE). Metode ini digunakan untuk menganalisis alternatifalternatif lokasi berdasarkan kriteria-
kriteria.Metode MPE akan membandingkan nilai kriteria dari berbagai alternatif lokasi.

Tahapan pemilihan alternatif wilayah potensional industri biopelletkulit ubi kayu di Kabupaten Jember berdasarkan MPE mengikuti prosedur sebagai berikut:

1. Menyusun alternatif keputusan yang akan dipilih.

2. Menyusun kriteria yang penting untuk dievaluasi.

3. Menentukan tingkat kepentingan setiap kriteria.

4. Menentukan skor masing-masing alternatif pada setiap kriteria.

5. Menentukan total skor setiap alternatif

Diagram alir pengolahan data untuk penentuan wilayah potensial industri biopellet kulit ubi kayu di Kabupaten Jember disajikan pada Gambar 1.

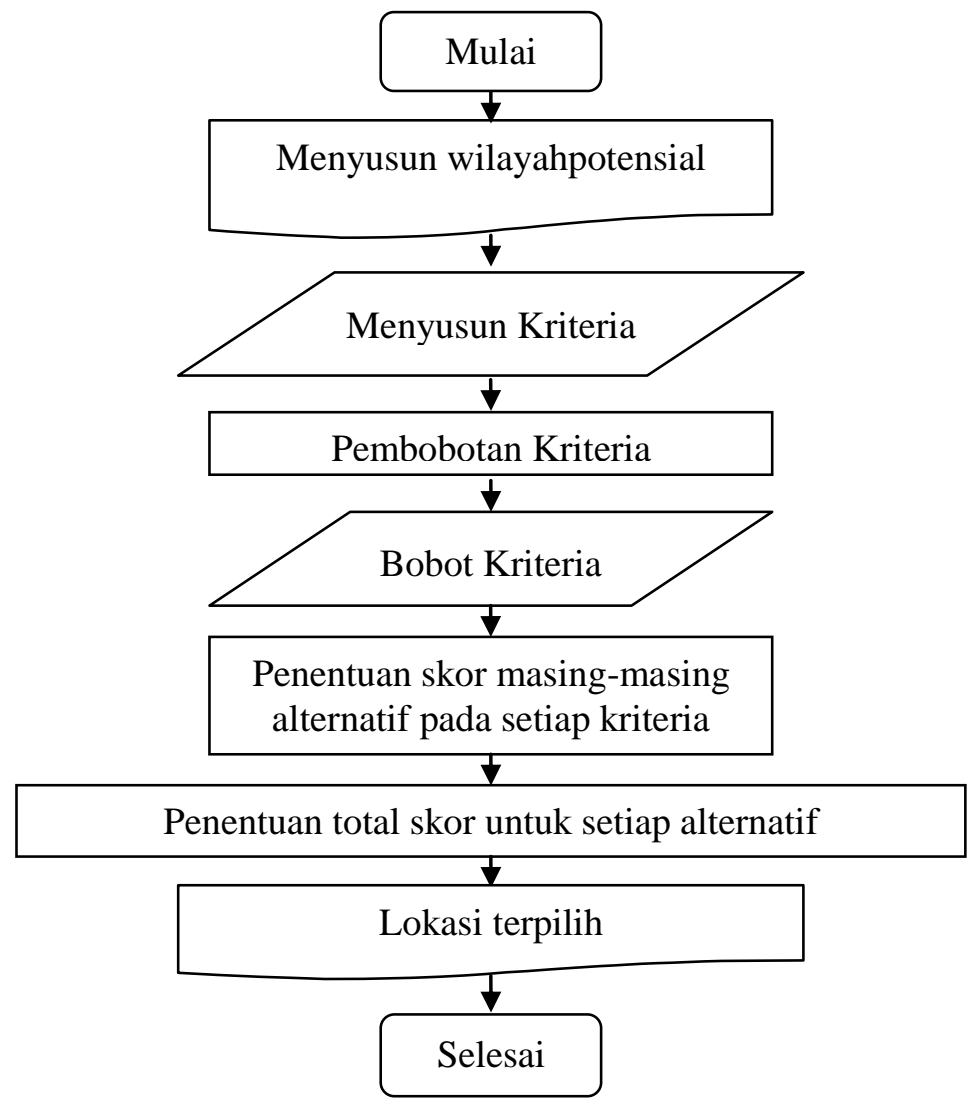

Gambar 1. Diagram alir penentuan wilayah potensial industri biopellet kulit ubi kayu di Kabupaten Jember 
Penentuan lokasi potensial industri biopellet kulit ubi kayu menggunakan rumus:

Total Nilai : $\sum$ (RK ij)

Keterangan :

Total Nilai $=$ Total Nilai alternatif ke-i

RK ij = Derajat kepentingan relatif kriteria ke-j pada pilihan keputusan i

\section{PEMBAHASAN}

\section{Analisis Penentuan Wilayah Potensial}

Penentuan wilayah potensial untuk mendirikan industri biopellet kulit ubi kayu menggunakan metode MPE (Metode Perbandingan Eksponensial). MPE merupakan salah satu metode pengambilan keputusan yang mengkuantifikasikan pendapat seseorang atau lebih dalam skala tertentu.Perhitungan secara eksponensial membuat perbedaan nilai antar kriteria dapat dibedakan tergantung kepada kemampuan orang yang menilai. Analisis penentuan wilayah potensial ini bertujuan untuk memberikan penilaian terhadap bobot MPE dan mengolah data dari beberapa lokasi dengan kriteria - kriteria yang sudah ditentukan. Metode ini digunakan untuk menentukan urutan prioritas lokasi yang potensial atau paling cocok dijadikan sebagai tempat industri biopellet.

Tahapan analisa setelah mengidentifikasi wilayah potensial di beberapa Kecamatan Kabupaten Jember adalah mencari faktor-faktor penentuan wilayah potensial. Penentuan wilayah potensial didasarkan pada 8 faktor $(\mathrm{A}-\mathrm{H})$ antara lain(a) Harga tanah per $\mathrm{m}^{2}$,(b) Infrastruktur (jalan, air dan listrik), (c) Jarak dengan pasar, (d) Ketersediaan bahan baku, (e) Ketersediaan bahan penunjang, (f) Ketersediaan tenaga kerja, (g) Sarana transportasi, dan (h) Upah tenaga kerja yang ada di daerah tersebut. Hasil dari nilai bobot faktor atau nilai kepentingan dalam pemilihan wilayah potensial dari masing-masing faktor disajikan pada Tabel 1.

Tabel 1 menunjukkan bahwa kriteria ketersediaan bahan baku mempunyai bobot tertinggi dibandingan dengan kriteria yang lain. Kriteria ketersediaan bahan baku mempunyai nilai bobot 9 . Hal ini
TKKj $=$ Derajat kepentingan kriteria keputusan ke-j; TKKj >0

$\mathrm{n} \quad=$ Jumlah pilihan keputusan

$\mathrm{m} \quad=$ Jumlah kriteria keputusan

(Marimin, 2004).

menunjukkan bahwa kriteria ketersediaan bahan baku sangat penting dalam menentukan wilayah potensial indutri biopellet. Pasokan bahan baku merupakan persyaratan yang penting dalam perencanaan suatu industri. Bahan baku merupakan kunci utama dalam kelangsungan proses produksi. Tanpa adanya bahan baku yang kontinuitas dan kuantitas yang banyak indutri tidak akan berjalan dengan lancar. Bahan baku untuk industri biopellet didapat dari limbah olahan industri ubi kayu dibeberapa daerah di Kabupaten Jember.

Kriteria tertinggi kedua adalah ketersediaan bahan penunjang dan ketersediaan tenaga kerja dengan nillai bobot 5. Bahan penunjang begitu penting terhadap kelangsungan proses produksi, tanpa adanya bahan penunjang seperti bahan bakar solar untuk jalannya mesin-mesin produksi maka proses produksi tidak bisa berjalan.Tenaga kerja berperan penting dalam keberhasilan proses produksi, meskipun teknologi yang digunakan di suatu perusahaan sudah menggunakan teknologi yang modern, namun masih membutuhkan tenaga kerja untuk mengoperasikannya.Tenaga kerja juga dipengaruhi oleh tingkat SDM, semakin tinggi tingkat SDM tenaga kerja maka akan tinggi pula tingkat jabatan yang diterima, dalam hal ini pelaku usaha dapat menyesuaikankebutuhan tenaga kerja yang dibutuhkan. Jumlah tenaga kerja hendaknya disesuaikan dengan tingkat produksi perusahaan. Jika perusahaan hanya dalam skala menengah ke bawah hendaknya tenaga kerja yang digunakan tidak terlalu besar sehingga dapat meningkatkan keuntungan.

Kriteria tertinggi ketiga adalah upah tenaga kerja dengan bobot 4 . Menurut Peraturan Gubernur Jawa Timur, Nomor 72 tahun 2014, menyatakan bahwa 
upah tenaga kerja di Kabupaten Jember termasuk pendapatan yang sedang atau berada di urutan ke 13 sebesar Rp

Tabel 1. Nilai bobot faktor
1.460.500 dari kebijakan yang ada di Propinsi Jawa Timur.

\begin{tabular}{llc}
\hline \multicolumn{1}{c}{ Kriteria } & Bobot \\
\hline A. Harga tanah per $\mathrm{m}^{2}$ & 3 \\
B. Infrastruktur (jalan, air dan listrik) & 3 \\
C. Jarak dengan pasar & 3 \\
D. Ketersediaan bahan baku & 9 \\
E. Ketersediaan bahan penunjang & 5 \\
F. Ketersediaan tenaga kerja & 5 \\
G. Sarana transportasi & 3 \\
H. Upah tenaga kerja & 4 \\
\hline
\end{tabular}

Sumber : Data primer diolah (2014)

Tabel 2. Penilaian alternatif wilayah potensial dengan perhitungan nilai MPE (Metode Perbandingan Eksponensial)

\begin{tabular}{|c|c|c|c|c|c|c|c|c|c|c|}
\hline \multirow[b]{2}{*}{ Alternativ } & \multicolumn{8}{|c|}{ Kriteria } & \multirow{2}{*}{$\begin{array}{l}\text { Nilai } \\
\text { Akhir }\end{array}$} & \multirow[t]{2}{*}{ Ranking } \\
\hline & A & B & $\mathrm{C}$ & D & $\mathrm{E}$ & $\mathrm{F}$ & G & $\mathrm{H}$ & & \\
\hline Jelbuk & 6 & 4 & 5 & 8 & 4 & 6 & 5 & 5 & 202.836 & I \\
\hline Tanggul & 5 & 8 & 6 & 5 & 6 & 5 & 7 & 6 & 199.355 & II \\
\hline Patrang & 3 & 6 & 8 & 3 & 7 & 7 & 8 & 6 & 198.428 & III \\
\hline Bangsal Sari & 4 & 8 & 7 & 3 & 7 & 6 & 6 & 7 & 197.547 & IV \\
\hline Panti & 5 & 7 & 5 & 4 & 6 & 6 & 6 & 6 & 192.252 & $\mathbf{V}$ \\
\hline Kaliwates & 3 & 6 & 8 & 2 & 8 & 6 & 8 & 6 & 189.770 & VI \\
\hline Rambi Puji & 6 & 6 & 7 & 3 & 6 & 6 & 7 & 6 & 188.772 & VII \\
\hline Mayang & 5 & 7 & 6 & 3 & 5 & 6 & 6 & 6 & 185.000 & VIII \\
\hline Kencong & 5 & 7 & 3 & 3 & 6 & 6 & 7 & 6 & 182.809 & IX \\
\hline Sukorambi & 5 & 6 & 6 & 3 & 5 & 5 & 6 & 6 & 176.122 & $\mathbf{X}$ \\
\hline Silo & 5 & 6 & 6 & 4 & 4 & 5 & 6 & 7 & 173.189 & XI \\
\hline Puger & 5 & 6 & 6 & 3 & 5 & 6 & 8 & 4 & 168.862 & XII \\
\hline Ledokombo & 7 & 6 & 2 & 4 & 4 & 3 & 5 & 6 & 160.780 & XIII \\
\hline Sumber Jambe & 4 & 7 & 3 & 4 & 4 & 3 & 6 & 7 & 157.864 & XIV \\
\hline Bobot MPE & 3 & 3 & 3 & 9 & 5 & 5 & 3 & 4 & & \\
\hline
\end{tabular}

Keterangan : (A) Harga tanah per $\mathrm{m}^{2}$,(B) Infrastruktur (jalan, air dan listrik), (C) Jarak dengan pasar, (D) Ketersediaan bahan baku, (E) Ketersediaan bahan penunjang, (F) Ketersediaan tenaga kerja, (G) Sarana transportasi, dan (H) Upah tenaga kerja.

Sumber : Data primer diolah (2014)

Jadi dengan tidak terlalu tingginya upah tenaga kerja di Kabupaten Jember, pelaku industri dapat menghemat biaya dan dapat dialokasikan di kebutuhan yang lain.

Kriteria yang terakhir adalah harga tanah per $\mathrm{m}^{2}$, infrastruktur (air, jalan dan listrik), jarak dengan pasar dan sarana transportasi dengan bobot 3. Harga tanah akan berpengaruh terhadap analisis investasi karena dengan harga yang lebih murah pelaku industri dapat menghemat biaya modal dan dapat dialokasikan ke kepentingan yang lain. Menurut Bank Danamon(2014) menyatakan bahwa, rata-rata harga tanah per $\mathrm{m}^{2}$ pada kecamatan Bangsal Sari sebesar Rp 590.000; pada Kecamatan Jelbuk sebesar Rp 100.000; pada Kecamatan Kaliwates sebesear Rp 405.000; pada Kecamatan Kencong sebesar Rp 63.000; pada Kecamatan Ledokombo sebesar Rp 47.000; pada Kecamatan Mayang sebesar Rp 34.250; pada Kecamatan Panti sebesar Rp 78.000; pada Kecamatan Patrang 
sebesar Rp 329.000; pada Kecamatan Puger sebesar 247.000; pada Kecamatan Rambi Puji sebesar Rp 378.500; pada Kecamatan Silo sebesar Rp 55.000; pada Kecamatan Sukorambi sebesar Rp 518.000; pada Kecamatan Sumber Jambe sebesar Rp 80.000; dan pada Kecamatan Tanggul sebesar Rp 184.000. Data harga tanah tiap kecamatan di Kabupaten Jember dapat memberikan informasi kepada pelaku usaha sehingga dapat mempertimbangkan wilayah potensial untuk Industri biopellet kulit ubi kayu dengan mudah.

Infrastruktur (air, jalan dan listrik) termasuk juga dalam prioritas penting dalam industri karena pada kenyataannya air, dan listrik mutlak harus terpenuhi serta akses jalan yang baik dan strategis dapat mendukung kelancaran distribusi maupun aktivitas industri.Jarak dengan pasar berpengaruh dengan peluang pasar yang mempunyai peranan cukup penting dalam menentukan keberhasilan suatu produk dan mempermudah jangkauan penjualan produk. Suatu produk tidak akan dikenal oleh kalangan masyarakat jika tidak mempunyai peluang pasar sekalipun produk tersebut diolah dengan teknologi yang mutakhir. Untuk mendapatkan peluang pasar maka perlu diadakan promosi. Peluang pasar diindikasikan dengan meningkatnya permintaan terhadap produk. Sarana transportasi berperan penting dalam menunjang beberapa faktor lainnya seperti mendukung pengadaan bahan baku dan melakukan distribusi atau pemasaran dengan mudah.

Berdasarkan penentuan bobot kriteria dari masing-masing faktor selanjutnya ditentukan wilayah potensial industri biopellet dan diperoleh nilai MPE dari masing-masing alternatif. Hasil perhitungan MPE untuk pemilihan wilayah potensial industri biopellet disajikan pada Tabel 2 .

Tabel 2 menunjukkan bahwa wilayah yang paling potensial untuk dikembangkan menjadi industri biopellet yaitu di wilayah Kecamatan Jelbuk dengan nilai akhir sebesar 202.836.Kecamatan Jelbuk layak menjadi wilayah potensial karena mempunyai banyak unit usaha olahan tape singkong yang juga dapat menghasilkan banyak limbah ubi kayu. Industri olahan tape singkong ada sebanyak 30 unit usaha yang terdaftar di Dinas Koperasi Kabupaten Jember di mana Jelbuk mempunyai unit usaha tape singkong terbesar kedua setelah Kecamatan Tanggul dengan 35 unit usaha.

Kecamatan Jelbuk memiliki harga tanah yang murah dibanding dengan wilayah lainnya, data sekunder dari Bank Danamon tahun 2014 menunjukkan harga tanah di Kecamatan Jelbuk yakni sebesar Rp $100.000 / \mathrm{m}^{2}$.Selain itu, jumlah tenaga kerja pengangguran di Kabupaten Jember pada tahun 2013 mencapai 45.619 jiwa (BPS, 2014). Menurut BPS Kabupaten Jember (2014) menyatakan bahwa, potensi sumber daya manusia di Kecamatan Jelbuk didominasi kaum muda di antara usia 15-19 tahun. Jadi pelaku usaha dapat dengan mudah untuk melakukan penyerapan tenaga kerja dengan asumsi tenaga kerja yang dibutuhkan untuk industri ini sebanyak 13 orang.

Kecamatan Jelbuk merupakan wilayah yang cukup strategis yakni berada di daerah utara Kabupaten Jember dengan jarak kurang lebih 11,8 km dari pusat KabupatenJember(Anonim, 2015).Lokasi yang strategis dekat dengan pasar dapat membantu untuk mengetahui perubahan selera konsumen dan mengurangi resiko kerusakan selama pengangkutan Posisi strategis Kecamatan Jelbuk menunjukkan bahwa, sarana transportasi mendukung aktivitas pelaku usaha untuk mendapat keuntungan karena industri dapat beroperasi dengan baik dan lancar. Menurut BPS Kabupaten Jember (2014) menyatakan bahwa, sarana transportasi yang tersedia di Kecematan Jelbuk antara lain angkutan umum roda 4 dan roda 2 , sehingga memudahkan warga untuk menjalankan aktivitas perdagangan dan aktivitas lainnya.

Menurut BPS Kabupaten Jember (2014) menyatakan bahwa, tingkat pendidikan di Kecamatan Jelbuk diklasifikasikan mulai dari SD sampai SMA/ sederajat.Kategori upah tenaga kerja, pelaku usaha diasumsikan mempunyai tiga kriteria yakni upah tenaga kerja harian, upah tenaga kerja tetap dan upah manajer.Upah tenaga kerja harian diasumsikan sebesar Rp 40.000 dengan klasifikasi tingkat pendidikan mulai SD sampai SMP/ sederajat.Upah tenaga kerja tetap diasumsikan memakai UMK kabupaten/ 
kota sebesar Rp 1.460.500 dengan klasifikasi tingkat pendidikan SMA/ sederajat. Upah tenaga kerja ketiga diasumsikan sebesar $\mathrm{Rp}$ 3.000.000 dengan ketentuan pelaku usaha sebagai manajer industri.Jadi dariasumsi tersebut, upahtenaga kerja di industri biopellet kulit ubi kayu dapat dikatakan layak sehingga pelaku usaha dapat menghemat biaya untuk dialokasikan pada kebutuhan yang lain.

Kriteria terakhir yakni infrastruktur (jalan, air dan listrik) dan kriteria ketersediaan bahan penunjang di Kecamatan Jelbuk. Infrastuktur jalan di wilayah ini meliputi jalan aspal $22,3 \%$ dan jalan sirtu $15,5 \%$ serta jalan tanah $16,6 \%$. Infrastruktur air di wilayah ini termasuk kategori melimpah, karena sebagian besar penduduk di wilayah ini bermata pencaharian di sektor pertaniandengan luas wilayah pertaniannya $81,05 \%$ dari total luas wilayah ini $42,18 \mathrm{~km}^{2}$. Infrastruktur listrik di wilayah ini dapat dikatakan cukup baik karenawilayah ini terdapat di jalan utama

\section{DAFTAR PUSTAKA}

Anonim. 2015. Google Maps. https://www.google.com/maps/dir/Kant or+Camat+Jelbuk,+Jelbuk,+Indonesia/ Alun+Alun+Kota+Jember,+Jember,+Ja wa+Timur,+Indonesia/.[13 Januari 2015].

[BPS] Badan Pusat Statistik Kabupaten Jember. 2014. Kabupaten Bondowoso dalam Angka. http://bondowosokab.bps.go.id/?hal $=$ publikasi_detil\&id=147 September 2014].

[DINKOP dan UMKM].Dinas Koperasi dan Usahs Mandiri Kecil Menengah Kabupaten Jember. 2013. Data UMKM Kabupaten Jember. Jember: DINKOP dan UMKM.

[DISPERINDAG dan ESDM].Dinas Perindustrian dan Perdagangan dan Energi Sumber Daya Mineral.2013. Direktori Perusahaan Industri Kecil dan Menengah Tahun 2013. Jember: DISPERINDAG dan ESDM. penghubung antara Kabupaten Jember dengan Kabupaten Bondowoso (BPS, 2014). Ketersediaan bahan penunjang di wilayah ini dapat dikatakan kurang mendukung karena tidak terdapat SPBU, tetapi dengan strategisnya wilayah ini maka kebutuhan bahan bakar mesin bisa terpenuhi dengan adanya SPBU di sekitar wilayah lain yang berdekatan dengan Kecamatan Jelbuk.

\section{KESIMPULAN}

Berdasarkan penelitian yang dilakukan, maka dapat diambil kesimpulan bahwa wilayah yang paling potensial untuk dikembangkan menjadi industri biopellet yaitu di wilayah Kecamatan Jelbuk. Kecamatan Jerbuk mempunyai kelebihan antara lain harga tanah yang murah, ketersediaan bahan baku dan ketersediaan tenaga kerja.

Hadiwiyoto, S. 2009. Penanganan dan Pemanfaatan Sampah. Jakarta : Yayasan Idayu.

Karoror. A. J. 2007. Strategi Diversifikasi Produk Buah Pala Negeri (Myristica argenta ware) di Kabupaten Fakfak.Tesis.Magister Manejemen dan Bisnis. Bogor: Institut Pertanian Bogor Marimin. 2004. Teknik dan Aplikasi Pengambilan Keputusan Kriteria Majemuk. Jakarta: Grasindo. 